the follow-up. Considering the whole SLE cohort, cardiovascular events were more frequent in obese patients $(14.7 \%)$ than in overweight $(7.6 \%)$ and normal weight (2.9\%) SLE patients (ANOVA test: $p=0.01$ ). Twentynine SLE patients with $\mathrm{BMI} \geq 25 \mathrm{Kg} / \mathrm{m}^{2}$ (BMI: $33.5 \pm 5.1 \mathrm{Kg} / \mathrm{m}^{2}$, age: $47.7 \pm 12.3$ years, disease duration: $11.9 \pm 9.0$ years; SLEDAl: $10.5 \pm$ 5.7, SLICC: $1.3 \pm 1.1$ ) underwent a scheduled low calories diet. A significant reduction in BMl was observed at 6 and 12 month follow-up [6.6 \pm $5.7 \%$ at 6 months FU $(p=0.001)$ and $7.0 \pm 7.2 \%$ at 12 months FU $(p=0.002)$, respectively] as well as a reduction in disease activity [SLEDAI at 6 months FU: $4.5 \pm 4.0(p=0.001)$ and at 12 months FU $(0.7 \pm 0.9$ ( $p<0.001)$ ]. Finally, a significant decrease of systemic inflammatory markers as C-Reactive Protein $(p<0.05)$ was observed in SLE patients who achieved $>5 \%$ weight loss compared to SLE patients who did not. Conclusion: Obesity represents a modifiable factor for improving outcomes among obese SLE. A weight loss obtained with a controlled diet may reduce cardiovascular events and reduce the state of chronic inflammation subtended by the activity of adipose tissue.

Disclosure of Interests: Maria Rita Gigante: None declared, Luca Petricca: None declared, Clara Di Mario: None declared, Anna Maria Paglionico: None declared, Valentina Varriano: None declared, Stefano Alivernini Speakers bureau: BMS, Barbara Aquilanti: None declared, Maria Rosaria Magurano: None declared, Giacomo Tanti: None declared, Barbara Tolusso: None declared, Gianfranco Ferraccioli Speakers bureau: BMS, Roche, Elisa Gremese Consultant for: AbbVie, BMS, Celgene, Janssen, Lilly, MSD, Novartis, Sanofi, UCB, Roche, and Pfizer, Speakers bureau: BMS, Speakers bureau: Roche, Speakers bureau: AbbVie, BMS, Celgene, Janssen, Lilly, MSD, Novartis, Sanofi, UCB, Roche, and Pfizer DOI: 10.1136/annrheumdis-2019-eular.5865

\section{AB0516 AUTOANTIBODY PROFILE ANALYSIS AND ITS ASSOCIATION WITH CLINICAL MANIFESTATIONS IN SYSTEMIC LUPUS ERYTHEMATOSUS PATIENTS}

Elena Grau García ${ }^{1}$, Francisco Miguel Ortiz Sanjuan ${ }^{1}$, Cristobal Pávez Perales ${ }^{1}$, Carmen Nájera Herranz ${ }^{1}$,Inés Cánovas Olmos ${ }^{1}$, Cristina Alcañiz Escandell ${ }^{1}$, Inmaculada Chalmeta Verdejo ${ }^{1}$, Marta De la Rubia Navarro ${ }^{1}$, Jorge Juan FragioGil $^{1}$, Roxana Gonzalez Mazario ${ }^{1}$, Luis Gonzalez Puig ${ }^{1}$, Jose Ivorra Cortés ${ }^{1,2}$, Isabel Martínez Cordellat ${ }^{1}$, Rosa Negueroles Albuixech ${ }^{1}$, Jose Eloy Oller Rodríguez ${ }^{1}$, Elvira Vicens Bernabeu ${ }^{1}$,David Hervás Marín ${ }^{3}$, Meritxell Fernandez Matilla ${ }^{4}$, Nagore Fernández-Llanio ${ }^{1}$, Juan Antonio Castellano Cuesta ${ }^{4}$ Carmen Riesco Bárcena ${ }^{2}$, Jose Andrés Román Ivorra ${ }^{1,2}$. ${ }^{1}$ Rheumatology Department. HUP La Fe, Valencia, Spain; ${ }^{2}$ Medical School. UCV, Valencia, Spain; ${ }^{3}$ Biostatistical Unit. IIS La Fe, Valencia, Spain; ${ }^{4}$ Rheumatology Section. H. Arnau de Vilanova, Valencia, Spain

Background: Systemic lupus erythematosus (SLE) is an autoimmune systemic disease characterized by autoantibody production. The presence of some of them is related to specific clinical manifestations. Previous studies have classified SLE patients according to an autoantibody profile, associating them to specific clinical groups.

Objectives: To define SLE patient groups according to an autoantibody profile and to analyze the correlation of these profiles to clinical manifestations, clinical activity and accumulated damage.

Methods: A cross-sectional observational study of SLE patients diagnosed according to SLICC 2012 criteria was conducted. A clinical and analytical evaluation was performed in all cases. Clinical manifestations were described according to RELESSER study. We selected 8 autoantibodies to classify SLE patients in different subgroups according to autoimmune similar profiles: anti-dsDNA, anti-Sm, anti-RNP, anticardiolipin IgG o $\operatorname{lgM}$ (aCL $\lg G / M)$, anti-B2microglobulin $\lg$ o $\lg M$ (aB2M $\lg G / M)$, lupus anticoagulant (LA), anti-Ro and anti-La. Biostatistical analysis was performed using software $R$ and immunological profiles were created according to previous study of Artim-Esen B et al. 2014.

Results: 142 SLE patients were evaluated (94.4\% female) with a mean age at diagnosis of 33.29 (13.53) and a mean time of disease evolution of 15.82 (10.56) years. Mean SLEDAI score was 5.91 (5.6) and mean SLICC value 1.1 (1.46). Frequency of the selected autoantibodies was: ANAs $87.3 \% \quad(n=124)$, anti-dsDNA $36.62 \% \quad(n=52)$, anti-Sm 9.2\% $(n=13)$, anti-RNP $3.5 \% \quad(n=5), \quad a C L \quad I g G / M \quad 20.15 \% \quad(n=27), \quad a B 2 M \quad l g G / M \quad 21.88 \%$ $(n=28)$, LA ANTI-LA? 26.27\% $(n=31)$, anti-Ro $45.07 \%(n=64)$ and anti-La $16.2 \%(n=23)$.

Profile $n \circ 2$ included SLE patients with anti-Sm/RNP positivity. Profile $n \circ 3$ included patients with anti-Ro/La positivity and not included in profile $n^{\circ} 2$. Profile $\mathrm{n}^{\circ} 4$ included patients with $\mathrm{aCL} \operatorname{lgG} / \mathrm{M}$ or aB2M $\operatorname{lgG} / \mathrm{M}$ or LA positivity and not included in previous profiles. Profile $n^{\circ} 5$ included patients who exclusively showed anti-DNA positivity. Profile $n^{\circ} 1$ included all patients excluded from the other profiles.
Depending on the results obtained, we analyzed autoantibody levels in order to assess its association with the presence of the described clinical affections. A significant association among hematological affection and high levels of anti-Ro $(\mathrm{P}<0.0001)$, anti-La $(\mathrm{P}=0.022)$ and anti-Sm $(\mathrm{P}=0.018)$ was observed. We also observed a tendency of presenting a higher rate of mucocutaneous affection, musculoskeletal and renal affection and Sjögren syndrome in patients classified in Profile 3.

Conclusion: Profile $\mathrm{n}^{\circ} 1$ patients (absence of autoantibodies) were diagnosed earlier and had a longer disease evolution, whereas Profile $n \circ 5$ patients (only anti-DNA positivity) were diagnosed at a mean age of 36 years and had a shorter disease evolution. We observed an association between the presence of anti-Ro/La and hematological affection, as well as high incidence of Sjögren syndrome in these subgroup of patients.

Disclosure of Interests: None declared

DOI: 10.1136/annrheumdis-2019-eular.5699

\section{AB0517 CORRELATION BETWEEN PATIENT-REPORTED OUTCOMES OF HEALTH-RELATED QUALITY OF LIFE AND CLINICAL ACTIVITY IN SYSTEMIC LUPUS ERYTHEMATOSUS PATIENTS}

Elena Grau García ${ }^{1}$, Jorge Juan Fragio-Gil ${ }^{1}$, Roxana Gonzalez Mazario ${ }^{1}$, Carmen Nájera Herranz ${ }^{1}$, Inés Cánovas Olmos ${ }^{1}$, Jose Ivorra Cortés ${ }^{1}$, Cristina

Alcañiz Escandell ${ }^{1}$, Inmaculada Chalmeta Verdejo ${ }^{1}$, Marta De la Rubia Navarro ${ }^{1}$ Luis Gonzalez Puig ${ }^{1}$, Isabel Martínez Cordellat ${ }^{1}$, Rosa Negueroles Albuixech ${ }^{1}$, Jose Eloy Oller Rodríguez ${ }^{1}$, Francisco Miguel Ortiz Sanjuan ${ }^{1}$, Cristobal

Pávez Perales ${ }^{1}$, Elvira Vicens Bernabeu ${ }^{1}$, David Hervás Marín ${ }^{2}$, Jose Andrés Román Ivorra ${ }^{1}{ }^{1}$ Rheumatology Department. HUP La Fe, v, Spain; ${ }^{2}$ Biostatistical Unit. IIS La Fe, Valencia, Spain

Background: Patient-Reported Outcomes (PROs) allow us to know the way the disease could affect patients, and maybe could not be detected in clinical measures. Among these, PROs of health-related quality of life (PRO-QL) represents patient evaluation of its health status and treatment which affects the functional, psychological, social and emotional capabilities. In fact, patients with the same health status could show different PROs-QL. In the case of systemic lupus erythematoSus (SLE), patients experience many inflammatory symptoms and all of them can affect the health-related quality of life in different ways.

Objectives: We aimed to measure the PRO-QL in SLE patients and correlate them with the clinical activity of the disease.

Methods: A cross-sectional observational study with SLE patients diagnosed according to SLICC 2012 criteria was performed. In all cases SLEDAI score was carried out, and patients full-filled questionnaires of fatigue (FACIT-FATIGUE), quality of life (EQ-5D-5L), disability (HAQ) and a Global Health Status Scale (GHS) (0-100). Biostatistical analysis with software $\mathrm{R}$ was performed, using the multivariate analysis of variance by Pillai test.

Results: 54 SLE patients $(91.84 \%$ female) participated in the study, with a mean age at diagnosis of $27.55 \pm 13.21$ years and a mean time of disease evolution of $20.45 \pm 9.7$ years. Mean SLEDAI score was $6.63 \pm 6.89$, with a $37.04 \%$ of patients with SLEDAl $>6$. The $64.66 \%$ of patients were under glucocorticoid treatment, $38.77 \%$ under immunosupressants (methotrexate, azatioprine o mycophenolate) and $51.02 \%$ under antimalarials.

Patients showed a mean score of $34.02 \pm 12.38$ in FACIT-FATIGUE, 0.72 \pm 0.26 in $E Q-5 D-5 L, 0.62 \pm 0.71$ in $\mathrm{HAQ}$ and $64.02 \pm 25.93$ in GHS

Statistical analysis showed correlation between SLEDAI score and the four questionnaires of PROs-QL $(P<0.001)$. Particularly in those cases with high clinical activity we observed low scores of EQ-5D-5L, FACITFATIGUE and GHS, and an increment in HAQ. We performed the previous analysis considering as correcting factors the age, years of disease evolution, glucocorticoid treatment, antimalarials and inmunosupressants We also obtained a correlation between clinical activity and PROs-QL $(\mathrm{P}=0.0107)$.

Conclusion: We observed a correlation between PROs-QL full-filled by SLE patients with the clinical activity of the disease, independently of glucocorticoid treatment, antimalarials and inmunosupressants, the age and the disease evolution.

Disclosure of Interests: None declared

DOI: 10.1136/annrheumdis-2019-eular.5661 